\title{
Modeling effects of increased larval mortality on bay anchovy population dynamics in the mesohaline Chesapeake Bay: evidence for compensatory reserve
}

\author{
James H. Cowan Jr ${ }^{1, *}$, Kenneth A. Rose ${ }^{2}$, Edward D. Houde ${ }^{3}$, Shyh-Bin Wang ${ }^{1}$, \\ John Young ${ }^{4}$
}

\author{
'University of South Alabama, Dauphin Island Sea Lab, 101 Bienville Blvd, Dauphin Island, Alabama 36528, USA \\ ${ }^{2}$ Coastal Fisheries Institute and Department of Oceanography and Coastal Sciences, Louisiana State University, Baton Rouge, \\ Louisiana 70803-7503, USA \\ ${ }^{3}$ Chesapeake Biological Laboratory, University of Maryland Center for Environmental Science, PO Box 38, Solomons, \\ Maryland 20688-0038, USA \\ ${ }^{4}$ Consolidated Edison Company of New York, 4 Irving Place, New York, New York 10003, USA
}

\begin{abstract}
We applied an individual-based population model to examine the potential compensatory scope of the bay anchovy Anchoa mitchilli in Chesapeake Bay. Model simulations were analyzed to estimate: (1) how losses of individuals in different life stages affect year-class production; (2) the changes needed in individual processes and, simultaneously in multiple processes, to offset a $50 \%$ increase in larval-stage mortality; and (3) population responses to increasing larval-stage mortality under conditions of presumed high compensatory potential. We hypothesize that, in response to lower densities, the bay anchovy population could compensate for increased larval mortality through increased growth rates, increased allocation of energy to reproduction, or reduced predation mortality as predators target other species. Simulation results indicate that late-larval and juvenile bay anchovy may be able to consume a significant fraction of their zooplankton prey, suggesting that anchovy is at abundances that can cause density-dependent growth in the Chesapeake Bay. However, densitydependent effects on prey resources alone had a limited buffering effect against a $50 \%$ reduction in larval-stage survival. The potential effect of losses of larvae on future production of a year class depended upon when during the larval stage individuals are removed from the population. Modeled alone, large changes in spawning intensity (no. of batches and eggs per batch), egg survival, or mortality of juveniles and adults were required to of fset increased larval mortality. When all processes were varied simultaneously, much smaller changes were required. Under a high compensation scenario, there was a strong dome-shaped response in adult production potential to increased larval mortality, such that highest adult production occurred when survival rate of larvae was reduced by as much as $60 \%$. While the information presently available to examine density-dependent population responses in bay anchovy is limiting, the modeled results indicate that the bay anchovy population in Chesapeake Bay potentially can regulate its abundance through simultaneous shifts in processes believed to be sensitive to population density.
\end{abstract}

KEY WORDS: Individual-based model - Bay anchovy Density-dependence Compensatory reserve

\section{INTRODUCTION}

The zooplanktivorous bay anchovy Anchoa mitchilli is among the most abundant fish of coastal bays and estuaries on the Atlantic coast of the USA (Hildebrand \& Schroeder 1928, Houde \& Zastrow 1991) and plays a

•E-mail: jcowan@jaguar1.usouthal.edu key role in trophic dynamics in those habitats (Baird \& Ulanowicz 1989, Wang \& Houde 1995). The anchovy contributes significantly to diets of commercially important piscivores in Chesapeake Bay (Baird \& Ulanowicz 1989, Hartman \& Brandt 1995), suggesting that limits on anchovy production may limit piscivore production (Hartman \& Brandt 1995). Moreover, it is possible that anchovy abundances are at levels where 
they can control abundance and biomass of their prey. Recent modeling (Luo \& Brandt 1993, Wang et al. 1997, Rose et al. 1999, in this issue) and field observational studies (Klebasko 1991, Wang \& Houde 1995) indicate that late-larval and juvenile bay anchovy may consume daily a significant fraction (possibly $\sim 30$ to $50 \%$ ) of the zooplankton standing stock in Chesapeake Bay in late-summer to fall when anchovy biomass peaks. High anchovy abundance and biomass may cause consumption rates on zooplankton that not only control zooplankton abundance but also result in densitydependent growth of anchovy, possibly affecting cumulative mortality and levels of recruitment (Cushing 1975. Houde 1987).

Past models of bay anchovy population dynamics have focused on effects of power plant entrainment and impingement (Polgar et al. 1988, Summers 1989, Loos \& Perry 1991). Power plant entrainment of bay anchovy larvae in the Patuxent River sub-estuary of Chesapeake Bay was estimated to reduce potential survival to the juvenile stage by 24 to $76 \%$ (Polgar et al. 1988). The past analyses and models have generally ignored the issue of compensatory reserve (densitydependent processes) and how it might affect population responses to reduced early-life-stage survival.

In this paper, which is a companion to Rose et al. (1999), we apply an individual-based model (IBM) to examine the potential compensatory scope of the bay anchovy population in the mesohaline Chesapeake Bay. Model simulations were analyzed to estimate: (1) how losses of individuals in different life stages affect yearclass production; (2) the magnitude of changes required in individual processes, and simultaneously in multiple processes, to offset a $50 \%$ increase in larvalstage mortality; and (3) population responses to increases in larval-stage mortality under presumed high compensatory potential conditions. We hypothesize that, at low densities, the bay anchovy population could compensate for increased larval mortality through increased growth rates, increased allocation of energy to reproduction (Bagenal 1966, Van Winkle et al. 1997), or reduced predation mortality if predators targeted other species (Hartman \& Brandt 1995). Increased energy allocated to reproduction could result in more spawning batches, more eggs per batch, or in higher quality eggs with higher survival potential (Bagenal 1973, Mann \& Mills 1979, Bromage et al. 1990).

Unfortunately, data presently available for bay anchovy do not permit resolution of whether these processes actually do change in response to anchovy density. Rather than attempt to determine functional relationships between these rates and density, we selected and imposed changes independent of simulated density. This approach avoids the need to specify func- tional relationships as such, and allowed us to determine how much compensation for increased larvalstage mortalities might be expected, assuming the selected processes responded to density.

\section{METHODS}

Model description. The IBM, described in detail by Rose et al. (1999), begins with spawning of individual bay anchovy females and simulates the growth and mortality of each female's progeny as individuals develop through the egg, yolk-sac larval, larval, juvenile, and adult stages. Exogenous feeding begins with the larval stage; juveniles are from 25 to $40 \mathrm{~mm}$ long; adults are $>40 \mathrm{~mm}$. Individuals are followed on a daily time step as they grow, spawn, and die. Surviving female adults become spawners of next year's progeny. Individuals can live multiple years; however, due to high mortality, individuals rarely live past Age 3 in simulations. Model simulations are for $50 \mathrm{yr}$, with each 365 day year beginning on Calendar Day 135 (May 15), the beginning of the spawning season.

For the egg and yolk-sac larval stages, each day's spawn of eggs (from pooled females) is followed through time; individuais are followed through larval, juvenile, and adult stages. The model tracks each individual's length $(L, \mathrm{~mm})$, dry weight ( $W, \mathrm{mg})$, age (d), life stage, day spawned, and day hatched.

Eggs and yolk-sac larvae develop at rates based upon temperature, and die at fixed rates per day. All feeding individuals (larvae, juveniles, and adults) consume zooplankton, and grow according to defined bioenergetics relationships. Prey encounters, attacks and captures, and mortality (probability of dying) of feeding individuals are treated stochastically using Monte Carlo techniques.

The model simulates daily dynamics in a single, well-mixed compartment (10 $\mathrm{m} \times 20 \mathrm{~m} \times 7.5 \mathrm{~m}$ deep). Environmental conditions in the compartment are daily mean water temperature, fraction of the $24 \mathrm{~h}$ day that is daylight, and the daily densities of zooplankton prey. For this version of the model, environmental and biological conditions are those expected in the mesohaline region of the Chesapeake Bay (Bay).

Spawners each year include those individuals that had been hatched in the mesohaline model box, plus a net immigration of individuals into the box. The actual number of spawners in the mesohaline region of the Bay varies each year somewhat independently of the number of survivors from the previous year because bay anchovy migrate to the southern portion of the Bay (as well as to coastal waters) for the winter; some return to the mesohaline Bay to spawn the next year (Wang \& Houde 1995). Although other alternatives 
have been explored in both Wang et al. (1997) and Rose et al. (1999), immigration into the mesohaline model box each year is represented in these simulations as a multiplier of the number of spawners hatched in the model box. Multiplier immigration represents the situation in which conditions for anchovy vary similarly for the entire population, including individuals derived from outside of the mesohaline region of the Bay. Thus, high numbers of survivors in the mesohaline model box would imply good conditions overall, and thus a high number of immigrants the next year. Immigrants are added on May 15 of each year as $55 \mathrm{~mm}$, Age 1 individuals in a 1:1 sex ratio.

Total population abundance is the number of adults (>40 mm) on May 15. Recruitment is defined as the number of young-of-the-year (YOY, Age 0) that have become adults $(40 \mathrm{~mm})$ by May 15 . Abundances and recruitment are expressed as numbers in the $1500 \mathrm{~m}^{3}$ model box. Production is based upon each feeding individual's (larva, juvenile, and adult) daily change in weight. Production is estimated by life stage and for year-classes over their lifetime. Mean values presented herein are based upon Years 4 to 50 of 50 yr simulations. The first 3 years of each simulation are not included to eliminate initial-condition effects.

Design of simulations. Results of 3 sets of simulations are presented in this paper. The first set consists of a baseline simulation and resulting estimates of lifestage-specific and total biomass production. This baseline simulation used multiplier immigration and is the same as that analyzed in more detail and compared to observational data by Rose et al. (1999). In this paper we also simulate the response of population production to losses of individuals in different life stages. A second set of simulations examines the magnitude of changes required in selected compensatory processes to offset a $50 \%$ reduction in larval survival. Effects of changes in levels of individual processes, as well as effects of simultaneous changes in all processes, are examined The third set of simulations compares the effects of a range of reductions in larval survival under baseline conditions to those with simultaneous changes in all processes combined specifically to result in high compensatory potential.

Baseline simulations and biomass production: Baseline conditions were run under conditions representative of the mesohaline region of the Bay (see Rose et al. 1999). Daily temperatures and zooplankton densities were specified based upon data from the Calvert Cliffs, Maryland area of the Bay. The model was configured to generate life-stage-specific densities, growth rates, mortality rates, and mean lengths-at-age that are similar to observed values. The magnitude of multiplier immigration required to stabilize the population was determined by trial and error.
The baseline simulation was used to estimate anchovy production. The change in weight of each anchovy for larvae, juveniles, Age 0 adults, and Age 1 to Age 3 adults $\left(\mathrm{d} W / \mathrm{d} t, \mathrm{mg} \mathrm{d} w \mathrm{~d}^{-1}\right)$ was summed over individuals for each day, and over days for each year. As individuals die during the simulation, they no longer contribute to production. Production of Age 1 and older adults was assigned to their respective year classes (e.g. a year class born in Year 5 included production of Age 1 in Year 6, Age 2 in Year 7, and Age 3 in Year 8). Year-class production for Year $t\left(P_{t}, \mathrm{mg}\right.$ dry $\left.w \mathrm{t} \mathrm{m}^{-3}\right)$ was computed as:

$$
\begin{aligned}
P_{t}= & \text { larval }+ \text { juvenile }_{t}+\text { Age } 0 \text { adult }_{t}+\text { Age } 1_{t+1} \\
& + \text { Age } 2_{t+2}+\text { Age } 3_{t+3}
\end{aligned}
$$

$P_{t}$ is the total production from individuals spawned in Year $t$ over their lifetime. $P$ was expressed as ing dry wt $\mathrm{m}^{-3}$, and per individual for each life stage. $P$ per number metamorphosing did not include larval production, and $P$ per number maturing did not include larval and juvenile production. Because the weights of eggs and yolk-sac larvae do not change in the model, production per hatchling and per first feeder required no adjustment to total production. Thus, life-stage-specific production ratios represent future production from the life stage represented in the denominator, forward.

Offsetting increased larval mortality (OLM) simulations: Model simulations estimated changes in levels of spawning intensity (number of batches and eggs per batch), egg survival, or mortality of juveniles and adults, that were required to offset an increase in larval mortality and 'restore' the bay anchovy population. Increasing the daily probability of larvae dying by $13 \%$ (multiply by 1.13 ) results in a mean mortality rate of $0.176 \mathrm{~d}^{-1}$ (compared to $0.156 \mathrm{~d}^{-1}$ in baseline simulations) and a $50 \%$ reduction in the mean number surviving to the juvenile stage.

We define restoration as occurring when the predicted mean total population abundance and recruitment were $\geq 90 \%$ of mean values in baseline simulations. To determine fecundities required to achieve restoration, batch fecundity was increased by multiplying the batch fecundity (eggs $\mathrm{g}^{-1}$ ) relationship (Eq. 4 in Rose et al. 1999) by 1.1, 1.3, 1.5, 1.7, 1.9, and 2.1. Number of spawning batches was increased by adding a constant $(0.05,0.10,0.15,0.20,0.25,0.80)$ in each case to calculate fractional progress towards spawning $\left(S_{p}\right)$, applying the following equation:

$$
S_{p}= \begin{cases}0.25 & \text { if } B T \leq 0.06 \\ 18.75 B T-0.875 & \text { if } 0.06<B T \leq 0.1 \\ 1.0 & \text { if } 0.1<B T \leq 0.83 \\ -18.75 B T-16.56 & \text { if } 0.83<B T \leq 8.87 \\ 0.25 & \text { if } B T>8.87\end{cases}
$$

where $B T=$ the number of batches completed divided by the maximum number of batches. Adding constants 
Table 1. Anchoa mitchilli. Simultaneous changes in an individual-based model of bay anchovy population dynamics in the number of egg batches, fecundity, and egg, juvenile and adult mortality used to identify minimal levels of changes needed for population restoration following a 50\% reduction in larval stage survival. The number in parentheses is the change necessary to each individual factor needed for restoration. Adding 0.20 to the fractional progress towards spawning as an individual change was assumed to be the biological upper limit

\begin{tabular}{|c|c|c|c|c|}
\hline $\begin{array}{l}\text { Magnitude of } \\
\text { simultaneous changes } \\
\text { relative to changes } \\
\text { in individual factors }\end{array}$ & $\begin{array}{l}\text { Multiplier of } \\
\text { fecundity } \\
(1.90)\end{array}$ & $\begin{array}{l}\text { Added to fractional } \\
\text { progress towards } \\
\text { spawning }(0.20)\end{array}$ & $\begin{array}{l}\text { Added to daily } \\
\text { egg survival } \\
\text { rate }(0.25)\end{array}$ & $\begin{array}{l}\text { Multiplier of } \\
\text { daily juvenile and } \\
\text { adult mortality } \\
\text { rate }(0.85)\end{array}$ \\
\hline $1 / 2$ & 1.45 & 0.1000 & 0.1250 & 0.925 \\
\hline $1 / 4$ & 1.22 & 0.0500 & 0.0630 & 0.963 \\
\hline $1 / 8$ & 1.11 & 0.0250 & 0.0313 & 0.981 \\
\hline
\end{tabular}

to the fractional progress towards spawning reduces the time (days) between batches (Rose et al. 1999). On the day that the cumulative sum of $S_{p}$ for a female $\left(\sum S_{p}\right)$ exceeds 1 , she spawns, her cumulative progress towards egg release is reset to 0 , and the process begins again. These constants, when added to $S_{p}$ resulted in the addition of $3,6,9,12,15$ and 30 batches to the $\sim 60$ batches spawned by females under baseline conditions. Adding the constant of 0.80 results in spawning every day and is included as the absolute upper limit on increases in the number of batches. Egg mortality was reduced by adding $0.10,0.15,0.20,0.25$, and 0.30 to the baseline egg survival rate of $0.20 \mathrm{~d}^{-1}$. Juvenile and adult mortality rates were lowered from baseline by multiplying assigned rates by $0.90,0.85,0.80$ and 0.75. For juveniles, this represented a range of assigned mortality rates of $0.032 \mathrm{~d}^{-1}$ (baseline) to 0.024 $\mathrm{d}^{-1}$ at the 0.75 reduced mortality level. For Age 0, Age 1 and older anchovy, the rates ranged from $0.0095 \mathrm{~d}^{-1}$ (baseline) to $0.0071 \mathrm{~d}^{-1}$ at the 0.75 reduced mortality level for Age 0 adults, and from $0.005 \mathrm{~d}^{-1}$ to $0.0038 \mathrm{~d}^{-1}$ for Age 1 and older adults.

We also varied numbers of egg batches, fecundity, and egg, juvenile and adult mortality rates simultaneously to identify minimal levels of combined changes needed to restore the population (Table 1). We began by simulating changes in each variable that individually resulted in restoration, and then continued to reduce these changes by about $50 \%$ until further reductions resulted in total population abundances and recruitment less than $90 \%$ of baseline values. We started by adding $\sim 12$ egg batches because spawning every day did not result in restoration of the population; the addition of 12 batches (20\% increase) was assumed to be a realistic biological upper bound based upon anchovy spawning frequency data from the lower Chesapeake Bay (Luo \& Muscik 1991). Average total population abundances and recruitment are shown for all simulations; time series plots of annual values are shown for selected levels of changes.
High compensatory potential (HCP) simulations: The model was used to assess population-level consequences of increased larval-stage mortality. Model simulations under baseline and high compensatory potential conditions were performed. HCP was arbitrarily imposed by (1) increasing the number of spawning batches of each female by 3 (from 60 to 63), (2) by increasing fecundity by multiplying by $1.10,(3)$ adding 0.10 to daily egg survival, and, (4) decreasing juvenile and adult mortality by multiplying their daily probability of dying by 0.90 . The potential magnitude of changes in these processes had been determined by examination of their variability in published and unpublished data for the mesohaline Bay (see Tables 1 $\& 3$ in Rose et al. (1999) for data sources). All of the changes that were imposed in the HCP simulation were generally much less than the values in the range of observed variations.

A total of 2750 -year simulations was performed. For each combination of baseline or $\mathrm{HCP}$, baseline larvalstage survival rate was decreased by $10,20,30,40,50$, 60 , and $75 \%$ to represent increased stress on the larval stage. The same number of immigrants was added to the population each year, as under baseline conditions. The assumption was that larval losses in the mesohaline region would not affect subsequent immigration of adults into this region of the Bay.

\section{RESULTS}

\section{Baseline}

Adding immigrant spawners in the baseline simulation as a multiplier of 0.70 times the number of survivors each year ( 420 to $906, \bar{x}=<622$ ) resulted in stable total population abundances and recruitment over time (see Fig. 8 in Rose et al. 1999). Mean total population abundance was 1046, and mean recruitment was 780 in the baseline simulation. Model-generated densities, mortality rates, growth rates, and diets were comparable to 
Table 2. Anchoa mitchilli. Modeled mean production (mg dry wt $\mathrm{m}^{-3}$ ) of bay anchovy by life stage, and for the year class in the baseline simulation. The value for all stages is the cumulative mean production for each of the life stages over its year class

\begin{tabular}{|lc|}
\hline Life stage & $\begin{array}{c}\text { Baseline simulation } \\
\text { (\% of total production) }\end{array}$ \\
\hline Larvae & $386.5(24.5 \%)$ \\
Juveniles & $692.9(44.0 \%)$ \\
Age 0 adults & $268.8(17.1 \%)$ \\
Age 1 adults & $193.4(12.3 \%)$ \\
Age 2 adults & $29.8(1.9 \%)$ \\
Age 3 adults & $4.8(0.3 \%)$ \\
All stages & $1576.2(100 \%)$ \\
\hline
\end{tabular}

field estimates (see Rose et al. 1999). On average, spawners hatched in the mesohaline model box comprised about $55 \%$ of the total spawners each year.

Our estimates of anchovy production are similar to those reported for the Chesapeake Bay. We used model-generated values that included immigrant contribution to production. Luo \& Brandt (1993) combined use of a bioenergetics model with acoustic estimates of biomass to generate an annual Age 0 anchovy production of $30770 \mathrm{~kg} \mathrm{~km} \mathrm{~km}^{-2} \mathrm{yr}^{-1}$. Our comparable production estimate (Age 0 minus larval production) was $36064 \mathrm{~kg} \mathrm{~km}^{-2} \mathrm{yr}^{-1}$. However, these 2 estimates of anchovy production are not independent, as Luo \& Brandt (1993) used, with permission, an unpublished version of our anchovy bioenergetics model for their analysis. Wang \& Houde (1995) reported Age 0 pro-

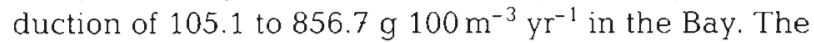
model-predicted mean value for Age 0 production

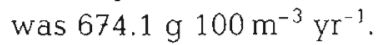

Mean values of production by life stage, and the combined-stages production of the year class, are presented in Table 2. Egg and yolk-sac larval production was zero. Mean lifetime production of a year class was $1576.2 \mathrm{mg}$ dry wt $\mathrm{m}^{-3}$. Age 0 life stages accounted for $86 \%$ of total year-class production, with juveniles accounting for about one-half of total Age 0 production. The result is similar to the findings of Wang \& Houde (1995), who reported that $\sim 88 \%$ of annual production in Chesapeake Bay occurred during the first 3 mo of life. High production in the juvenile lifestage is attributable to relatively rapid growth compared to adults, and relatively low mortality compared to larvae.

Values of $P$ meta ${ }^{-1}$ and $P$ matur $^{-1}$ are 4 orders of magnitude greater than $P$ egg $^{-1}$ values and $\sim 100$-fold greater than $P$ hatch ${ }^{-1}$ and $P \mathrm{ff}^{-1}$ values (Table 3 ). Eggs and yolk-sac larvae do not grow in the model; thus, the increase from production per egg to per hatchling to per first feeder is due to mortality. Losses of individual eggs and yolk-sac larvae reduce future production
Table 3. Anchoa mitchilli. Mean values of production per number of bay anchovy entering each life stage (mg dry wt ind.$^{-1}$ ) in the baseline simulation. Ratios expressed as $P$ (mg dry wt $\mathrm{m}^{-3}$ ) per spawned egg, per hatchling (yolk-sac larva), per first feeding larva, per number metamorphosing (Meta), and per number maturing (Matur)

\begin{tabular}{|lc|}
\hline Life stage & Baseline simulation \\
\hline Egg & 0.042 \\
Hatch & 0.167 \\
First feed & 0.783 \\
Meta & 86.6 \\
Matur & 103.3 \\
\hline
\end{tabular}

potential much less than losses of individual juveniles and adults. The potential effect of losses of larvae on future production depends upon when during the larval stage individuals are removed from the population. Losses of early-stage larvae, just after first-feeding would have minimal effects on future production (losses would be computed using the very small $P \mathrm{ff}^{-1}$ ratio), whereas losses of late larvae nearing metamorphosis would significantly reduce population production (losses would be computed using the much larger $P$ meta ${ }^{-1}$ ratio)

\section{Offsetting increased larval mortality}

Density-dependent increases in anchovy growth based solely upon feedbacks from prey abundance (see Rose et al. 1999 for more details) did little to compensate for a $50 \%$ reduction in larval-stage survival. A $50 \%$ reduction in larval survival resulted in a mean total population abundance $58 \%$ of baseline (604 versus 1046; Fig. 1a) and a mean recruitment $52 \%$ of baseline (407 vs 780). A smaller effect was predicted for total population abundance compared to recruitment because total population abundance includes immigrants each year, which were unaffected by increased larval-stage mortality. Density-dependent increases in juvenile growth resulted in Age 1, 2, and 3 adults that were $-4 \mathrm{~mm}$ longer than in baseline simulations, which increased egg production. Mean number of eggs per female increased from 68189 in baseline to 78294 in OLM simulations. Juvenile growth and survival increased from means of $0.54 \mathrm{~mm} \mathrm{~d}^{-1}$ and $35 \%$ to $0.67 \mathrm{~mm} \mathrm{~d}^{-1}$ and $45 \%$ in OLM simulations. However, these changes did not compensate for the $50 \%$ reduction in larval survival.

Restoration was achieved for compensatory increases in fecundity and survival (Fig. 1a,c,d), but not for increased spawning batches (Fig. 1b). Model simulations behaved consistently, in the sense that mean total population abundance and recruitment increased with 


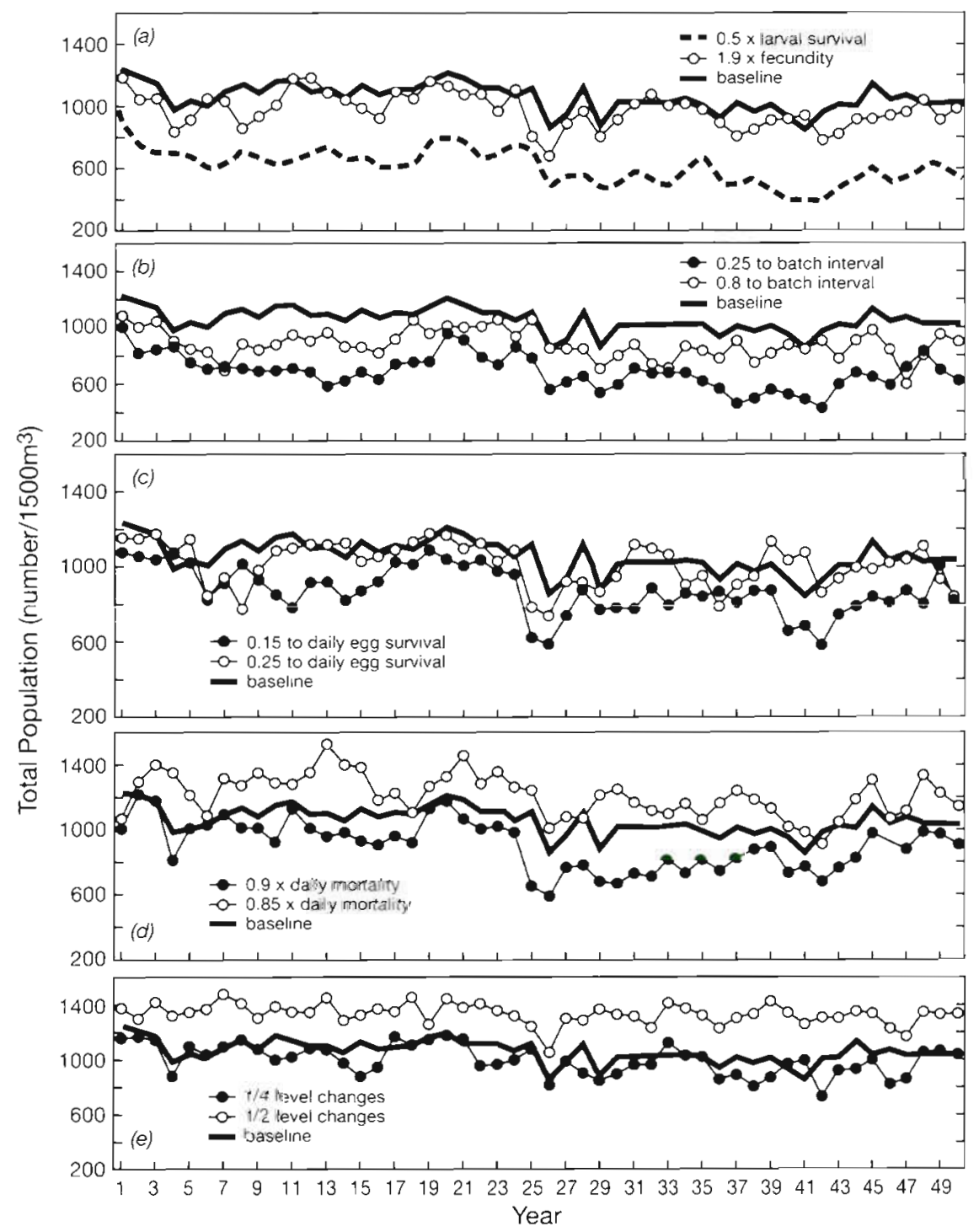

Fig. 1. Anchoa mitchilli. Annual total baseline population abundance (solid line) of bay anchovy, population abundance after a $50 \%$ reduction in larval survival (dashed line), and population abundance for a subset of the changes in selected processes necessary to restore the population following a $50 \%$ reduction in larval survival: (a) 1.9 times fecundity, (b) 0.25 and 0.80 added to the interval between spawning batches, (c) 0.15 and 0.25 added to the daily egg survival rate, (d) 0.9 and 0.85 times the daily juvenile and adult mortality rate, and (e) all of these processes simultaneously at $1 / 4$ to $1 / 2$ the magnitude of changes in individual factors needed for restoration increasing compensatory potential. Spawning every day (adding as many as 30 additional egg batches) was not sufficient to restore the population to baseline levels (Fig. 1b). The smallest changes needed in the other processes for restoration were: increasing fecundity by a factor of 1.9 (Fig. 1a), increasing egg survival rate by $0.25 \mathrm{~d}^{-1}$ (Fig. 1c), and multiplying juvenile and adult mortality by 0.85 (Fig, 1d).

Substantially smaller changes in compensatory processes were required for restoration when processes were varied simultaneously $(\sim 1 / 4$ the magnitude of individual changes; Table 1, Fig. 1e). Changes required for restoration with simultaneous, versus individual, changes were 1.22 vs 1.9 for fecundity, 0.063 $\mathrm{d}^{-1}$ vs $0.25 \mathrm{~d}^{-1}$ for egg survival, and 0.963 vs 0.85 for juvenile and adult mortality rate. Simultaneous changes also included the addition of $\sim 3$ spawning batches.

\section{High compensatory potential}

Under baseline conditions (no reduction in larval survival), HCP conditions resulted in significantly higher total population abundances and recruitment. Mean total population abundance was $-25 \%$ higher compared to baseline (1315 vs 1046). Mean recruitment increased by $>1.4$-fold (1187 vs 780 ).

HCP conditions enabled the simulated anchovy population to withstand up to a $60 \%$ reduction in larvalstage survival (Fig. 2a,b). Under baseline conditions, which relied only on density-dependent effects on prey abundance for compensation, total population abundances and recruitment of bay anchovy decreased with increased larval mortality. Under HCP conditions, total population abundances and recruitment remained above baseline means for $\leq 60 \%$ reductions in larval-stage survival. 


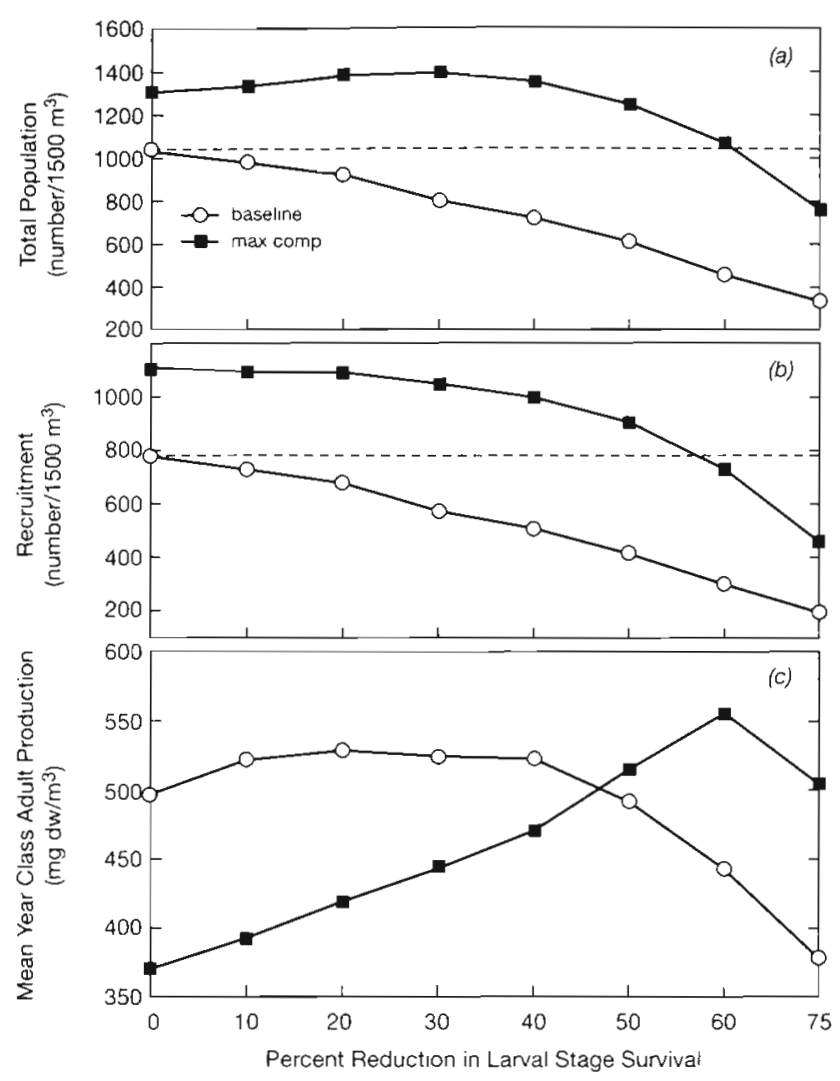

Fig. 2. Anchoa mitchilli. Model predictions of mean (a) total population abundance, (b) recruitment, (c) year-class adult production in relation to larval survival

Year-class adult production (mg dry wt $\mathrm{m}^{-3}$ ) peaked when percent larval-stage survival was reduced by 20 to $40 \%$ in baseline and $60 \%$ in HPC simulations (Fig. 2c). Density-dependent effects on growth and survival solely due to anchovy effects on prey abundance (i.e. baseline conditions) resulted in a relatively flat, although dome-shaped, relationship between production and reductions in larval survival. HPC conditions resulted in consistent increases in adult production with decreasing larval stage survival, until a sharp peak was reached at about $60 \%$ reduced larval-stage survival. Low production when larval-stage survival is high indicated that strong density-dependent controls on juvenile growth rates had major effects on biomass production.

Fig. 3. Anchoa mitchilli. Predicted relationship between bay anchovy cohort biomass and time (d), compared to a conceptualized marine larval fish cohort (insert) redrawn from Houde (1997)

\section{DISCUSSION}

In Chesapeake Bay, bay anchovy is an 'opportunistic' life history strategist (Winemiller \& Rose 1992) that exhibits, among other life-history traits, a large intrinsic rate of population increase due to rapid larval growth (Houde \& Zastrow 1993) and rapid population turnover rates (Wang \& Houde 1995). This life-history strategy is geared toward cohort persistence and is illustrated by the relationship between cohort biomass and time (d) shown in Fig. 3, which compares the anchovy relationship with that for a conceptualized marine larval fish cohort (Fig. 3 insert) described by Houde (1997). Cohort success in marine fishes may be dependent upon a 'transisiton size' in early life where weight-specific growth $(G)$ first exceeds instantaneous mortality $(Z)$ and a cohort's biomass then begins to increase. Because successful cohorts eventually must gain biomass and cohort-specific mortality rates usually are highest in the first few days after hatching, Houde (1997) hypothesized that larval cohorts must reach their transition size quickly if they are to persist. Cohort biomass will increase most rapidily at the size (or time) where $G / Z$ is maximum. Our IBM results, based upon the mean of $50 \mathrm{yr}$ in the baseline simulation of a daily cohort spawned on July 11, indicate that bay anchovy cohorts may indeed reach the transition size quickly (i.e. when larvae are 8 to $10 \mathrm{~mm} \mathrm{TL).} \mathrm{The}$ ratio $G / Z$, and the rate of biomass increase, is maximum in the late-larval to juvenile stage, 35 to $55 \mathrm{~d}$ post hatch.

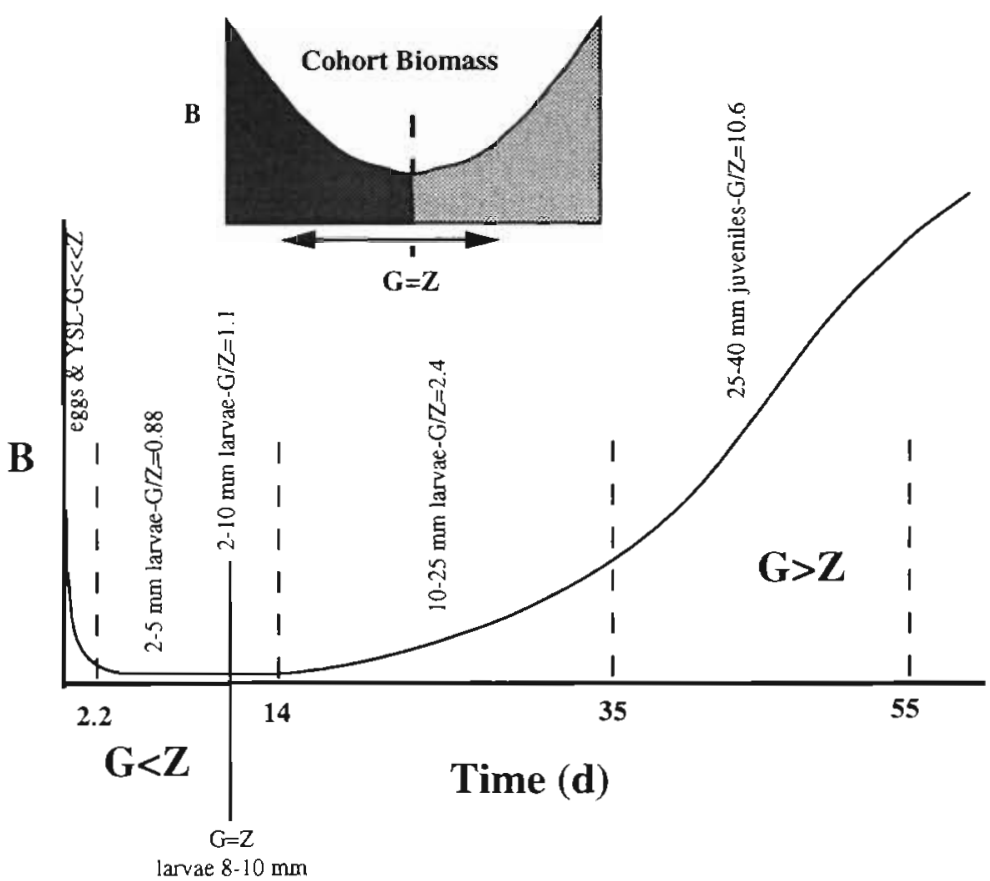


Because bay anchovy apparently is able both to minimize the transition size and attain maximum $G / Z$ at young age, it undoubtedly is well suited to repopulate the mesohaline Chesapeake Bay each spring, even in the face of continuous high predation mortality on adults (Hartman \& Brandt 1995). The opportunistic life-history strategy permits efficient recolonization of habitats (Winemiller \& Rose 1992). However, rapid population increases may result in dense populations, leading to a high potential for density-dependent regulation. This point was examined by Houde (1989), who suggested that a species' potential for densitydependent regulation is related to its ratio of $G_{\max }$ (maximum $G$ ) to $Z$, and by its weight at metamorphosis $\left(W_{\mathrm{m}}\right)$ to weight at hatching $\left(W_{0}\right)$. Bay anchovy, with quite low $G_{\max } / Z$ and high $W_{\mathrm{m}} / W_{0}$ has a relatively strong potential for density-dependent response to change in growth rate (Houde 1989).

Compensatory reserve develops in response to high population levels acting via population effects on some limiting resource (here zooplankton prey). In our baseline simulation, years of high egg production resulted in lowest first-year survival. For example, for the 5 years of highest egg production the ratio of first year survivors to number of eggs produced was 1.2 to $1.3 \times$ $10^{-5}$, compared to 1.5 to $1.7 \times 10^{-5}$ in the 5 years of lowest egg production (see Rose et al. 1999, Fig. 13). This result supports the findings of Houde (1989), who showed that simulated density-dependent declines in larval anchovy growth rate as egg (or larval) density increased could stabilize recruitment levels.

Whether process rates, including the simple growthrate related changes described above, in bay anchovy actually respond to density requires empirical confirmation. Evidence of such responses has been observed uncommonly in marine systems (Koslow et al. 1995, Trippel 1995), or is contradictory. For example, changes in fecundity could provide a compensatory mechanism serving to stabilize fish populations under anthropogenic sources of mortality (Nikolsky 1969, Nikolsky et al. 1973, Rothschild et al. 1989\}. However, doubt about whether density-dependent changes in adult growth and fecundity can be large enough to stabilize recruitment (Shepherd \& Cushing 1980), the lack of a clear relationship between egg production and subsequent recruitment (Koslow 1992), and the lack of data on how fecundity varies in relation to physical and biological conditions, have not confirmed a compensatory role for fecundity (Koslow et al. 1995, Trippel 1995). Interannual changes in fecundity of northern anchovy Engraulis mordax (Lasker 1985) and Atlantic herring Clupea harengus (Almatar \& Bailey 1989) were unrelated to changes in adult abundance; however, variation in fecundity consistent with density dependence has been reported for other species
(Nikolsky 1969, Bagenal 1973, Nikolsky et al. 1973, Rothschild 1986, Rothschild \& Fogarty 1989).

Additionally, Trippel (1995) reviewed data from northwest Atlantic groundfish populations and reported that age and size at maturity decreased by 15 to $55 \%$, and by as much as $30 \%$, respectively, in exploited cod Gadus morhua and haddock Melanogrammus aeglefinus from Canadian waters between 1959 and 1992. He presumed the observed shift to an earlier age and size at maturity to be a compensatory response of stressed populations (populations that have undergone substantial reductions in size) to maintain or achieve maximal reproductive output. However, he further suggested that stocks comprised of a broad range of ages and sizes are able to spawn more eggs of a large range in size (as discussed below), and that these eggs are spawned over a longer period of time than eggs produced by stocks comprised of young fish (Trippel 1995).

Two examples that support changes in fecundity acting as a significant compensatory response have been reported for Japanese anchovy and orange roughy. In response to long-term declines (1970 to 1984) in stock levels and numbers of large adults, Japanese anchovy underwent a change in 'mode of life' whereby the spawning potential of small ( 7 to $12 \mathrm{~cm}$ ) anchovy increased dramatically (Funakoshi 1992). Nutritional condition and the proportion of small females that matured and spawned increased. Spawning frequency changed from once every 4 to $5 \mathrm{~d}$ for large $(12$ to $16 \mathrm{~cm})$ females to every 2 to $3 \mathrm{~d}$ for small anchovy. Batch fecundity increased by 1.2 to 2.2 -fold, although egg size decreased. In combination, these changes in reproductive potential of smaller fish resulted in almost constant egg production over the period of decline (Funakoshi 1992). Recently, Koslow et al. (1995) showed that individual fecundity of orange roughy increased by $20 \%$ after the stock was fished down to around $50 \%$ of virgin biomass. The authors suggested that the compensatory increase in individual fecundity, combined with an apparent $17 \%$ increase in the proportion of females spawning, limited the expected decline in population egg production during 1987-1992 to $\sim 15 \%$, despite the $50 \%$ reduction in spawning biomass

We believe that the modeled changes required in individual compensatory processes of bay anchovy necessary to acheive population restoration under a $50 \%$ increase in larval-stage mortality may be unrealistically large. For example, an $\sim 2$-fold increase in fecundity was required to offset the increased larval mortality. Batch fecundity in bay anchovy is positively related to female weight (Zastrow et al. 1991). Potentially, if more food is available to female spawners, increased growth rate resulting in larger size will increase individual fecundity. This response is built 
directly into our IBM via density-dependent effects on prey resources (Rose et al. 1999). A second way to increase fecundity is for females to divert more energy to reproduction; we also simulated increases in batch size (i.e. eggs $\mathrm{g}^{-1}$ ) per bay anchovy female, and changes in egg quality. Spawning females continue to grow rapidly during the spawning season (Zastrow et al. 1991, Newberger \& Houde 1995), implying that there is surplus energy available that could be allocated to increased egg production (Van Winkle et al. 1997, reviewed by Kjorsvik et al. 1990). In the Japanese sardine Sardinops melanostictus, biochemical composition of eggs is largely influenced by the quantity and nutritional quality of the food which the females have eaten (Lasker \& Theilacker 1962). Nutritional quality of food provided to broodstock significantly increased total number of eggs spawned, percentage of eyed eggs and egg hatchability (Takeuchi et al. 1981, Watanabe et al. $1984 \mathrm{a}, \mathrm{b}, \mathrm{c}$ ). In a recent field study of Japanese sardine in Tosa Bay, Morimoto (1996) found positive relationships between gonad index $(G I)$ and condition factor of spawning females $(\sim 2$-fold change in $G I)$, ovary weight and lipid content of muscle ( -3 -fold change in lipid content), and yolk volume and condition factor ( 1.4-fold increase in yolk volume). These results lead Morimoto (1996) to speculate that sardines which had accumulated enough nutrients before the spawning season would produce more and bigger eggs.

A $\sim 2$-fold increase in fecundity due to changes in bay anchovy size, or in the number of eggs per batch is unlikely. There is a morphological upper limit on the number of eggs that can be spawned (Roff 1982). The weight of mature ovaries in some fish species is an exponential allometric function of body weight (MacKinnin 1972, Delahunty \& deVlaming 1980, Erickson et al. 1985, Sibly \& Calow 1986). While the exponent in this allometric function tends to be $>1.0$, implying that the proportion of the energy budget devoted to reproduction generally increases with body size (Van Winkle et al. 1997), the relationship for bay anchovy between number of eggs released per batch and female weight is linear (Zastrow et al. 1991). This implies that female anchovy size would have to double in response to anchovy density to produce the $\sim 2$-fold increase in population fecundity necessary for restoration, although Luo \& Musick (1991) showed that variation in relative daily fecundity (mean no. eggs $\mathrm{g}^{-1}$ body weight $\mathrm{d}^{-1}$ ) is large enough to allow a near doubling of egg output, if the variabiltiy is related to ration as the authors speculated. If it were morphologically possible for females to produce larger batches, converting female growth during the spawning season to egg production could result in the $\sim 2$-fold increase in fecundity needed for population restoration. Assuming that an average female spawner is $53 \mathrm{~mm}$ and $200 \mathrm{mg}$ dry wt, and grows by 1 to $2 \%$ in weight per day during the spawning season (Wang \& Houde 1993, Rose et al. 1999 for review of data), she could produce 667 to 1333 additional $0.003 \mathrm{mg}$ eggs $\mathrm{d}^{-1}$ if all somatic growth were diverted to reproduction. In the baseline simulation, a $200 \mathrm{mg}$ female produces $\sim 700$ eggs per batch.

Serial spawners such as bay anchovy also may respond to changes in food availability by changing the frequency of spawning and number of spawns. Both the interval between successive spawnings (Wooton 1977) and the numbers of spawnings during a season (Townsend \& Wooton 1985) can be related to ration. Experimental results have confirmed rationdependent variation in batch-fecundity and interspawning interval in the Japanese anchovy, with a lag of 11 to $21 \mathrm{~d}$ between increased ration and increased fecundity (Tsuruta \& Hirose 1989). Based upon studies in Tampa Bay, Florida, Peebles et al. (1996) inferred that bay anchovy may be an 'income breeder' (following Stearns 1993) that spawns soon after energy for egg production becomes available, implying that observed seasonal and spatial patterns in egg production can largely be explained by variation in metabolic rate and adult ration. However, increasing the number of batches per female by as many as 30 (i.e. $\sim 1.5$-fold increase in fecundity) in our modeled population did not result in restoration.

The $30 \%$ increase in bay anchovy egg survival required for restoration also is unlikely. Egg survival potential could be related to anchovy density via a change in egg quality, cannibalism, or density-dependent predation. Food availability during the spawning season may influence size or quality of eggs spawned (reviewed by Kjorsvik et al. 1990, Bromage 1995). Egg size has been shown to increase with body size for many species (e.g. Buckley 1967, Rogers \& Westin 1981, Lobon-Cervia et al. 1986, Hislop 1988, Kjesbu 1989, Zastrow et al. 1989, Monteleane \& Houde 1990, Buckley et al. 1991b, Kjesbu et al. 1992, Blom et al. 1994), but information about the potential for increased egg size to improve egg and larval viability is contradictory. There is little empirical evidence that large bay anchovy females produce larger or heavier eggs (Zastrow et al. 1991). In the closely related Atlantic herring Clupea harengus, Bradford \& Stephenson (1992) concluded that egg number is favored over egg quality (i.e. egg size) by larger females. Japanese anchovy responded to low population levels by producing more, but smaller eggs (Funakoshi 1992).

Nevertheless, many studies have shown that while egg hatchability often is unaffected, larger eggs hatch into heavier embryos (reviewed by Kjorsvik et al. 1990) and larger larvae usually grow faster in length and 
weight (e.g. Blaxter \& Hempel 1963, Theilacker 1981, Knutsen \& Tilseth 1985, Rana 1985, Monteleone \& Houde 1990, Baynes \& Howell 1996). Survival of a cohort tends to be positively related to growth rates during early larval stages (Anderson 1988, Cowan et al. 1996) and also may be positively related to body size at hatching (Rosenberg \& Haugen 1982, Miller et al. 1988, Buckley et al. 1991a, Blom et al. 1994). In contrast, the hypothesis that large eggs produce large larvae that persist longer on endogenous energy reserves, or experience significant increases in survival rate, has not been supported by some studies (e.g. Chambers et al. 1989, Secor 1990, Pepin \& Myers 1991, Rijnsdorp \& Vingerhoed 1994, Blom et al. 1995; also see review by Kjorsvik et al. 1990).

Egg cannibalism, which has been shown to be a significant cause of density-dependent mortality in other anchovies, apparently is not important for bay anchovy. Close relationships between daily egg mortality rates (in \% $\mathrm{d}^{-1}$ ) and spawning biomass concentrations (in $\mathrm{g} \mathrm{m}^{-2}$ ) have been demonstrated for several other anchovies (Smith et al. 1989). For example, simultaneous samples of eggs and adults for estimates of daily egg production indicate that cannibalism amounts to 20 to $30 \%$ of total daily egg mortality in northern anchovy Engraulis mordax and Peruvian anchoveta E. ringens (MacCall 1981, Alheit 1987. 1993). Cannibalism rates for bay anchovy have not been estimated in the field, but Cowan \& Houde (1993) showed that anchovy consumed very few of their own eggs when alternative zooplankton prey was present with eggs in mesocosm enclosures. Field studies of bay anchovy gut contents in Chesapeake Bay and elsewhere produced little or no evidence of cannibalism (Vazquez 1989, Klebasko 1991, Peebles et al. 1996).

A third potential mechanism for density-dependent egg or larval mortality, i.e. density-dependent responses by predators, also is not supported by empirical data for bay anchovy. Gelatinous zooplankton may consume large numbers of bay anchovy eggs and larvae in Chesapeake Bay (Cowan et al. 1992, Cowan \& Houde 1993, Purcell et al. 1994). However, eggs and larvae constitute a relatively small proportion of the diet of the jellyfish predators (Purcell 1992); thus, it seems unlikely that these predators will exhibit strong responses to changes in bay anchovy density.

The $15 \%$ reduction in juvenile and adult mortality required for population restoration is possible if mortality rate is size-dependent, or if predators respond in a density-dependent manner. But, evidence for such responses is weak. The likelihood of significant growth-rate related, density-dependent changes in juvenile and adult bay anchovy mortality rates is difficult to assess. In our simulations, juvenile and adult bay anchovy died at fixed rates independent of size because of the lack of empirical information suggesting otherwise. Thus, changes in growth rates due to density-dependent feedbacks on prey resources act only to change the duration of the relatively short juvenile stage ( 25 to $40 \mathrm{~mm}$ TL) where daily mortality rates are estimated to be $\sim 30 \%$ higher than for adults. However, because bay anchovy biomass peaks during the late-larval to juvenile stage in fall, and juvenile prey consumption rates are high, it is juvenile density that induces the density-dependent relationship between egg production and survival to Age 1 in our IBM (see Fig. 13 in Rose et al. 1999). Additional reductions in juvenile mortality of 25 to $30 \%$ in relation to decreased density are not possible because we constrained the upper limit of juvenile (and adult) growth rate based upon empirical observations (Rose et al. 1999). However, if either juvenile or adult mortality rate were sizedependent, we may be underestimating the magnitude of this density-dependent feedback.

Reductions in juvenile and adult mortality rates due to density-dependent responses of their predators are possible if predators target other forage species due to reduced profitability when anchovy densities are low (Werner \& Hall 1974, Townsend \& Hughes 1981, Werner \& Mittlebach 1981, Hartman \& Brandt 1995). Reductions in mortality of $15 \%$ cannot be dismissed as unrealistic. But, if the relationship between predation mortality and bay anchovy density is strong, it is more likely to be associated with high anchovy density and follow a non-linear 'S-shaped' curve (Type III functional response) as described for predation by small mammals on insects (Holling 1959). Such a response has been demonstrated for predation on juvenile fishes (Murdoch 1969, Peterman \& Gatto 1978, Lockwood 1980, van der Veer 1986) and indicates either a numerical response whereby the number of predators increases, or a functional response whereby each individual predator attacks more prey, or a combination of the two (Hassell 1978, also see Bailey 1994 for review).

When all factors were varied simultaneously, our IBM simulations showed that much smaller changes in the number of spawning batches, fecundity, and egg, juvenile and adult mortality rates were required to offset the increased larval mortality rate. Changes required for population restoration were about $1 / 4$ the levels required in individual factors. Thus, further examination of these processes and how they act in combination is warranted. A density-dependent component for spawning (batches, fecundity, etc.) and for mortality rates can easily be implemented in the anchovy model. Further field and laboratory study of anchovy spawning and mortality rates, especially in relationship to anchory densities, would help to calibrate the IBM, improve its predictive capability, and add to our understanding of compensatory potential. 
The changes required for population restoration when processes were varied simultaneously are consistent with, and similar to, changes assumed under HPC conditions. The 1/4-level versus HPC changes were: 1.22 vs 1.10 multiplier of fecundity; 3 more spawning batches for both simultaneous and $\mathrm{HPC} 0.063$ vs $0.10 \mathrm{~d}^{-1}$ added to daily egg survival rate; and, $0.963 \mathrm{vs}$ 0.90 multiplier of daily juvenile and adult mortality. Fecundity was the only required change that was larger under the 1/4-level, compared to HPC changes.

The particular set of changes that we imposed in this IBM example is not unique. A different algorithm or different initial values would produce a different set of simultaneous changes necessary for restoration, and many alternative combinations of changes can restore the population. However, it is likely that many such combinations include compensatory changes of which the bay anchovy is capable, based upon what is known about bay anchovy growth rate potential and variability in fecundity, as well as upon information from other fish species, including other anchovies. Thus, we believe that density-dependent responses required to offset a $50 \%$ increase in larval mortality when processes vary simultaneously are realistic.

Indeed, our IBM simulations represent a broad range of compensatory potential, and the population level consequences of this range can be seen in Fig. 2. Significant reductions in larval-stage survival generally result in lower total population numbers and recruitment under all scenarios. When density-dependence is weakest (i.e. baseline), population production initially increases only slightly, then declines after a $40 \%$ reduction in larval-stage survival (Fig. 2). Under the HPC scenario, there is a strong dome-shaped response to increased larval mortality such that highest adult production occurs when as many as $60 \%$ of the larvae are killed.

In all cases, zooplankton prey is the limiting resource. Increased potential to produce a strong year class by increasing egg production and stage-specific survival results in high population levels, stronger density-dependent feedbacks on prey, and stronger abridgement of production in the population. Based on our results, it is possible to envision how increased predation or other anthropogenic removals could affect the bay anchovy population, given knowledge of physiological responses to changes in anchovy density, and how this knowledge could be used in individual-based models. In a recent study, Wang et al. (1997) provided evidence that in some years the Chesapeake Bay population of bay anchovy may produce multiple peaks in egg output, or may delay spawning to more closely match prey production. Although a relationship between such changes and bay anchovy density is speculative at present, strong potential for densitydependent regulation is indicated.
Acknowledgements. This research was sponsored by the Electric Power Research Institute under contract RP2932-2 (DOE No. ERD-87-672) with the U.S. Department of Energy, under contract No. DE-AC05-96OR22464 with Lockheed Martin Energy Research Corp. This is Publication No. 4781 of the Environmental Sciences Division, Oak Ridge National Laboratory. Support for E.D.H. was provided by National Science Foundation Grants OCE9203307 and OCE9521512.

\section{LITERATURE CITED}

Alheit J (1987) Egg cannibalism versus egg predation: their significance in anchovies. S Afr J Mar Sci 5:67-470

Alheit $J$ (1993) Spawning frequency of Peruvian anchovies taken with a purse seine. NMFS Tech Memo 36, US Department of Commerce

Almatar SM, Bailey RS (1989) Variation in the fecundity and egg weight of herring (Clupea harengus L.). Part I. Studies in the Firth of Clyde and northern North Sea. J Cons Int Explor Mer 45:113-124

Anderson JT (1988) A review of size-dependent survival during pre-recruit stages of fishes in relation to recruitment. J Northw Atl Fish Sci 8:55-66

Bagenal TB (1966) The ecological and geographical aspects of the fecundity of the plaice. J Mar Biol Assoc UK 46: $161-186$

Bagenal TB (1973) Fish fecundity and its relations with stock and recruitment. In: Parrish BB (ed) Fish stocks and recruitment. Proceedings of a Symposium, Aarhus, Denmark, July 1970. Rapp PV Réun Cons Int Explor Mer 164: $186-198$

Bailey KM (1994) Predation on juvenile flatfish and recruitment variability. Neth J Sea Res 32:175-189

Baird D, Ulanowicz RE (1989) The seasonal dynamics of the Chesapeake Bay ecosystem. Ecol Monogr 59:329-364

Baynes SM, Howell BR (1996) The influence of egg size and incubation temperature on the condition of Solea solea (L.) larvae at hatching and first feeding. J Exp Mar Biol Ecol 199:59-77

Blaxter JHS, Hempel G (1963) The influence of egg size on herring larvae (Clupea harengus). J Cons Int Explor Mer 28:211-240

Blom G, Svasand T, Jorstad KE, Ottera H, Paulsen OI, Holm JC (1994) Comparative survival and growth of two strains of Atlantic cod (Gadus morhua) through the early life stages in a marine pond. Can $J$ Fish Aquat Sci 51: $1012-1023$

Bradford RG, Stephenson RL (1992) Ëgg weight, fecundity, and gonad weight variability among northwest Atlantic herring (Clupea harengus) populations. Can J Fish Aquat Sci 49:2045-2054

Bromage N (1995) Broodstock management and seed quality - general considerations. In: Bromage NR, Roberts RJ (eds) Broodstock management and egg and larval quality. Blackwell Science, Ltd, Oxford, p 1-14

Bromage N, Hardiman P, Jones J, Sprongate J, Bye V (1990) Fecundity, egg size and total egg volume differences in 12 stocks of rainbow trout (Oncorhynchus mykiss Richardson). Aquacult Fish Mngmt 21:269-284

Buckley LJ, Smigielski AS, Halavik TA, Caldarone EM, Burns BR, Laurence GC (1991a) Winter flounder Pseudopleuronectes americanus reproductive success. I. Among location variability in size and survival of larvae reared in the laboratory. Mar Ecol Prog Ser 74:117-124

Buckley LJ, Smigielski AS, Halavik TA, Caldarone EM, Burns BR, Laurence GC (1991b) Winter flounder Pseudopleu- 
ronectes americanus reproductive success. Il. Effects of spawning time and female size on composition and viability of eggs and larvae. Mar Ecol Prog Ser 74:125-135

Buckley RV (1967) Fecundity of steelhead trout (Salmo gairdneri) from Alsea River, Oregon. J Fish Res Board Can 24 : 917-926

Chambers RC, Leggett WC, Brown JA (1989) Egg size, female effects, and the correlations between early life history traits of capelin, Mallotus villosus: an appraisal at the individual level. Fish Bull US 87:515-523

Cowan JH Jr, Houde ED (1.993) Relative predation potentials of scyphomedusae, ctenophores and planktivorous fish on ichthyoplankton in Chesapeake Bay. Mar Ecol Prog Ser 95:55-65

Cowan JH Jr, Birdsong RS, Houde ED, Priest JS, Sharp WC, Mateja $G$ (1992) Enclosure experiments on survival and growth of black drum eggs and larvae in lower Chesapeake Bay. Estuaries 15:492-502

Cowan JH Jr, Houde ED, Rose KA (1996) Size-dependent vulnerability of marine fish larvae to predation: an individualbased numerical expenment. ICES J Mar Sci 53:23-37

Cushing DH (1975) Marinc cology and fisheries. Cambridge Univ Press, Cambridge

Delahunty $G$, deVlaming VL (1980) Seasonal relationships of ovary weight, liver weight and fat stores with body weight in the gold fish (Carassius auratus). J Fish Biol 16:5-13

Erickson DL, Hightower JE, Grossman GD (1985) The relative gonadal index: an alternative index for quantification of reproductive condition. Comp Biochem Physiol 81A: $117-120$

Funakoshi S (1992) Relationship between stock levels and the population structure of the Japanese anchovy. Mar Behav Physiol 21:1-84

Hartman KJ, Brandt SB (1995) Predatory demand and impact of striped bass, bluefish, and weakfish in the Chesapeake Bay: applications of bioenergetics models. Can J Fish Aquat Sci 52:1667-1687

Hassell MP (1978) Arthropod predator-prey systems. Princeton Univ Press, Princeton

Hildebrand SF, Schroeder WC (1928) Fishes of the Chesapeake Bay, Smithsonian Institution Press, Washington DC

Hislop JRG (1988) The influence of maternal length and age on the size and weight of the eggs and the relative fecundity of the haddock, Melanogrammus aeglefinus, in British waters. J Fish Biol 32:923-930

Holling CS (1959) The components of predation as revealed by a study of small mammal predation on the European pine sawfly. Can Ent 91:293-320

Houde ED (1987) Fish early life dynamics and recruitment variability. Am Fish Soc Symp 2:17-29

Houde ED (1989) Comparative growth, mortality, and energetics of marine fish larvae: temperature and implied latitudinal effects. Fish Bull US 87:47 1-495

Houde ED (1997) Patterns and consequences of selective processes in teleost early life histories. In: Chambers RC, Trippel E (eds) Selective processes in teleost life histories. Chapman and Hall, New York, p 173-196

Houde ED, Zastrow CE (1991) Habitat requirements for Chesapeake Bay living resources, 2nd edn. In: Funderburk SL, Jordan SJ, Mihursky JA, Riley D (eds) Bay anchovy, Chap 8. Chesapeake Bay Program, Annapolis, MD

Houde ED, Zastrow CE (1993) Ecosystem- and taxa-specific dynamic and energetics properties of larval fish assemblages. Bull Mar Sci 53:290-335

Houde ED, Gamble JC, Dorsey SE, Cowan JH Jr (1994) Drifting mesocosms: the influence of gelatinous zooplankton on mortality of bay anchovy Anchoa mitchilli eggs and yolk-sac larvae. ICES J Mar Sci 51:383-394

Iguchi K, Yamaguchi M (1994) Adaptive significance of interand intrapopulational egg size variation in ayu Plecoglossus altivelis (Osmeridae). Copiea 1994:184-190

Kjesbu OS (1989) The spawning activity of cod Gadus morhua L. J Fish Biol 34:195-206

Kjesbu OS, Kryvi H, Sundby S, Solemdal P (1992) Buoyancy variations in eggs of Atlantic cod (Gadus morhua L.) in relation to chorion thickness and egg size: theory and observations. J Fish Biol 41:581-599

Kjorsvik E, Mangor-Jensen A. Holmefjord I (1990) Egg quality in fishes. Adv Mar Biol 26:71-113

Klebasko $\mathrm{MJ}$ (1991) Feeding ecology and daily ration of bay anchovy (Anchoa mitchili) in the mid-Chesapeake Bay. MS thesis, Univ Maryland, College Park

Knutsen GM, Tilseth S (1985) Growth, development and feeding success of Atlantic cod larvae Gadus morhua related to egg size. Trans Am Fish Soc 114:507-511.

Koslow JA (1992) Fecundity and the stock-recruitment relationship. Can J Fish Aquat Sci 49:210-217

Koslow JA, Bell J, Virtue P, Smihin DC i 1995) Fecundity and its variability in orange roughy: effects of population density, condition, egg size, and senescence. J Fish Biol 47: $1063-1080$

Lasker RE (1985) What limits clupeoid production? Can J Fish Aquat Sci 42 (Suppl 1):31-38

Lasker RE, Theilacker GH (1962) The fatty acid composition of the lipids of some Pacific sardine tissues in relation to ovarian maturation and diet. J Lip Res 3:60-64

Lobon-Cervia J, Montanes C, de Sosta A (1986) Reproductive ecology and growth of a population of brown trout (Salmo trutta L.) in an aquifer-fed stream of Old Castile (Spain). Hydrobiologia 135:81-94

Lockwood SJ (1980) Density-dependent mortality in 0-group plaice (Pleuronectes platessa L.) populations. J Cons Int Explor Mer 39:148-153

Loos JJ, Perry ES (1991) Larval migration and mortality rates of bay anchovy in the Patuxent River. Proc 14th Annual Larval Fish Conference, Beaufort, NC

Luo J, Brandt SB (1993) Bay anchovy Anchoa mitchilli production and consumption in mid-Chesapeake Bay based on a bioenergetics model and acoustic measures of fish abundance. Mar Ecol Prog Ser 98:223-236

Luo J, Musick JA (1991) Reproductive biology of the bay anchovy in Chesapeake Bay. Trans Am Fish Soc 120:701-710

MacCall AD (1981) The consequences of cannibalism in the stock-recruitment relationship of planktivirous pelagic fishes such as Engraulis. IOC Workshop Rept 28:201-220

MacKinnon JC (1972) Summer storage of energy and its use for winter metabolism and gonad maturation in Americam plaice (Hippoglossoides platessoides). J Fish Res Board Can 29:1749-1759

Mann RHK, Mills CA (1979) Demographic aspects of fish fecundity. Symp Zool Soc Lond 44:161-177

Miller TJ, Crowder LB, Rice JA, Marschall EA (1988) Larval size and recruitment mechanisms in fishes: toward a conceptual framework. Can J Fish Aquat Sci 45:1657-1670

Monteleone DM, Houde ED (1990) Influence of maternal size on survival and growth of striped bass Morone saxatilis Walbaum eggs and larvae. J Exp Mar Biol Ecol 140:1-11

Morimoto $H$ (1996) Effects of maternal nutritional conditions on number, size and lipid content of hydrated eggs in the Japanese sardine from Tosa Bay, southwestern Japan. In: Watanabe Y, Yamashia Y, Oozeki Y. (eds) Survival strategies in early life stages of marine resources. AA Balkema, Yokohama, p $3-12$ 
Murdoch WW (1969) Switching in general predators: experiments on predator specificity asnd stability of prey populations. Ecol Monogr 39:335-354

Newberger TA, Houde ED (1995) Population biology of bay anchovy (Anchoa mitchilli) in the mid-Chesapeake Bay. Mar Ecol Prog Ser 116:25-37

Nikolsky G (1969) Theory of fish population dynamics as the background for rational exploitation and management of fishery resources. Oliver \& Boyd, Edinburgh

Nikolsky G, Bogdanov A, Lapin Y (1973) On fecundity as a regulatory mechanism in fish population dynamics. Rapp PV Réun Cons Int Explor Mer 164:174-177

NOAA, NMFS (1991) Status of fishery resources of the northeastern United States for 1991. NOAA Tech Memo NMFSF/NEC-86

Peebles EB, Hall JR, Tolley SG (1996) Egg production by the bay anchovy Anchoa mitchilli in relation to adult and larval prey fields. Mar Ecol Prog Ser 131:61-73

Pepin P, Myers RA (1991) Significance of egg and larval size to recruitment variability of temperate marine fish. Can J Fish Aquat Sci 48:1820-1828

Peterman RM, Gatto M (1978) Estimation of functional responses of predators on juvenile salmon. J Fish Res Board Can 35:797-808

Polgar TT, Turner MA, Summers JK (1988) Effect of power plant entrainment on the population dynamics of the bay anchovy (Anchoa mitchilli). Ecol Model 41:201-218

Purcell JE (1992) Effects of predation by the scyphomedusan Chrysaora qunquecirrha on the zooplankton populations in Chesapeake Bay, USA. Mar Ecol Prog Ser 87:65-76

Purcell JE, Nemazie DA, Dorsey SE, Houde ED, Gamble JC (1994) Predation mortality of bay anchovy (Anchoa mitchilli) eggs and larvae due to scyphomedusae and ctenophores in Chesapeake Bay. Mar Ecol Prog Ser 114: $47-58$

Rana KJ (1985) Influence of egg size on the growth, onset of feeding, point-of-no-return, and survival of unfed Oreochromis mossambicus fry. Aquaculture 46:119-131

Rijnsdorp AD, Vingerhoed B (1994) The ecological significance of geographical and seasonal differences in egg size in sole Solea solea (L.). Neth J Sea Res 32:255-270

Roff DA (1982) Reproductive strategies in flatfish: a first synthesis. Can J Fish Aquat. Sci 39:1686-1698

Rogers BA, Westin DT (1981) Laboratory studies of the effects of temperature and delayed initial feeding on development of striped bass larvae. Trans Am Fish Soc 110 : $100-110$

Rose KA, Cowan JH, Clarke ME, Houde ED, Wang SB (1999) An individual-based model of bay anchovy population dynamics in the mesohaline region of Chesapeake Bay. Mar Ecol Prog Ser 185:113-132

Rosenberg AA, Haugen AS (1982) Individual growth and size-selective mortality of larval turbot (Scopthalmus maximus) reared in enclosures. Mar Biol 72:73-77

Rothschild BJ (1986) Dynamics of marine fish population. Harvard Univ Press, Cambridge

Rothschild BJ, Fogarty MJ (1989) Spawning-stock biomass: a source of error in recruitment/stock relationships and management advice. J Cons Int Explor Mer 45:131-135

Rothschild BJ, Osborn TR, Dickey TD, Farmer DM (1989) The physical basis for recruitment variability in fish populations. J Cons Int Explor Mer 45:136-145

Secor DH (1990) The early life history of natural and hatchery-produced striped bass, Morone saxatilis (Walbaum). PhD dissertation, University of South Carolina, Columbia

Sibly R, Calow P (1986) Why breeding earlier is always worthwhile. J Theoret Biol 123:311-319
Smith PE, Santander H, Alheit J (1989) Comparison of the mortality rates of Pacific sardine, Sardinops sagax, and Peruvian anchovy, Engrawlis ringens, eggs off Peru. Fish Bull US 87:497-508

Stearns S (1993) The evolution of life histories. Oxford Univ Press, New York

Summers JK (1989) Simulating the indirect effects of power plant entrainment losses on an estuarine ecosystem. Ecol Model 49:31-47

Summers JK, Rose KA (1987) The role of interactions among environmental conditions in controlling historical fisheries variability. Estuaries 10:255-266

Takeuchi M, Idhii S, Ogiso T (1981) Effect of dietary vitamin $E$ on growth, vitamin $E$ distribution and mortalities of the fertilized eggs and fry in ayu Plecoglossus altivelis. Bull Tokai Reg Fish Res Lab 104:111-122

Theilacker GH (1981) Effect of feeding history and egg size on the morphology of jack mackerel, Trachurus symmetricus, larvae. Rapp PV Réun Cons Int Explor Mer 178: $432-440$

Townsend CR, Hughes RN (1981) Maximizing net energy returns from foraging. In: Townsend $\mathrm{CR}$, Calow $\mathrm{P}$ (eds) Physiological ecology: an evolutionary approach to resource use. Blackwell Science, Ltd, Oxford, p 86-108

Townsend TJ, Wootton RJ (1984) Effects of food supply on the reproduction of the convict cichlid, Cichlasoma nigrofasciatum. J Fish Biol 24:91-104

Trippel EA (1995) Age at maturity as a stress indicator in fisheries. Bioscience 45:759-771

Tsuruta Y, Hirose K (1989) Internal regulation of reproduction in the Japanese anchovy (Engraulis japonica) as related to population fluctuation. Can Spec Publ Fish Aquat Sci 108 . $111-119$

van der Veer HW (1986) Immigration, settlement, and density-dependent mortality of a larval and early postlarval 0 group plaice (Pleuronectes platessa) population in the western Wadden Sea. Mar Ecol Prog Ser 29:223-236

Van Winkle W. Holcomb BD, Jager HI, Tyler JA, Whitaker SY, Shuter BJ (1997) Regulation of energy acquisition and allocation to respiration, growth and reproduction: simulation model and example using rainbow trout. In: Chambers RC, Trippel EA (eds) Early life history and recruitment in fish populations. Chapman and Hall, New York, p 103-137

Vazquez AV (1989) Energetirs, trophic relationships and chemical composition of bay anchovy, Anchoa mitchilli, in the Chesapeake Bay. MS thesis, Univ Maryland, College Park

Wang SB, Houde ED (1993) Energy storage and dynamics in the bay anchovy. Anchoa mitchilli. Mar Biol 121:219-227

Wang SB, Houde ED (1995) Distribution, relative abundance, biomass and production of bay anchovy Anchoa mitchilli in the Chesapeake Bay. Mar Ecol Prog Ser 121:27-38

Wang SB, Cowan JH Jr, Rose KA, Houde ED (1997) Variability in recruitment and production potential of bay anchovy Anchoa mitchilli in mid-Chesapeake Bay. J Fish Biol 5. (Suppl A): 101-120

Watanabe T, Itoh A, Murakami A, Tsukashima Y, Kitajima C, Fujita $S$ (1984a) Effect of nutritional quality of diets given to broodstock on the verge of spawning on reproduction of red sea bream. Bull Jpn Soc Sci Fish 50:1023-1028

Watanabe T, Ohhashi S, Itoh A, Kitajima C, Fujita S (1984b) Effect of nutritional composition of diets on chemical components of red sea bream broodstock and eggs produced. Bull Jpn Soc Sci Fish 50:503-515

Watanabe T, Takeuchi T, Saito M, Nishimura K (1984c) Effect of low protein-high calory or essential fatty deficiency diet 
on reproduction in rainbow trout. Bull Jpn Soc Sci Fish 50:1207-1215

Werner EE, Hall DJ (1974) Optimal foraging and the size selection of prey by the bluegill sunfish (Lepomis macrochirus). Ecology 55:1042-1052

Werner EE, Mittlebach GG (1981) Optimal foraging: field tests of diet choice and habitat switching. Am Zool 21:813-822

Winemiller KO, Rose KA (1992) Patterns of life-history diversification in North American fishes. Can J Fish Aquat Sci 49:2196-2220

Wootton RJ (1977) Effect of food limitation during the breed-

Editorial responsibility: Kenneth Heck $J_{I}$ (Contributing Editor), Dauphin Island, Alabama, USA ing season on the size, body composition and egg production of female sticklebacks (Gasterosteus aculeatus). $J$ Anim Ecol 46:823-834

Zastrow CE, Houde ED, Saunders EH (1989) Quality of striped bass (Morone saxatilis) eggs in relation to river source and female weight. Rapp PV Réun Cons Int Explor Mer 191:34-42

Zastrow CE, Houde ED, Morin LG (1991) Spawning, fecundity, hatch-date frequency and young-of-the-year growth of bay Anchoa mitchilli in mid-Chesapeake Bay. Mar Ecol Prog Ser 73:161-171

Submitted: September 22, 1997; Accepted: December 30, 1998 Proofs received from author(s): July 22, 1999 